Rev. Hist., N²7, vol. 2, Julio-Diciembre 2020: 211-235

ISSN 0717-8832

https://doi.org/10.29393/RH27-16EHMH10016

\title{
Educación humanista, cultura clásica y legitimidad republicana: la batalla oratoria entre Andrés Bello y José Joaquín de Mora (1828-1830)
}

\author{
Humanist education, classical culture and republican legitimacy: the oratory battle \\ between Andrés Bello and José Joaquín de Mora (1828-1830)
}

\author{
María Gabriela Huidobro Salazar: ORCID: https://orcid.org/0000-0001-9980-6175¹
}

\section{RESUMEN:}

Entre abril y julio de 1830, la elite ilustrada de Chile fue testigo de un ácido debate académico entre los directores del Liceo de Chile y del Colegio de Santiago, José Joaquín de Mora y Andrés Bello. El objetivo de este artículo consiste en analizar los discursos de dicha polémica en relación con el contexto político y cultural que la enmarcó. La hipótesis sugiere que, junto con traslucir una lucha partidista, los conceptos y tópicos desarrollados en la querella ofrecen un testimonio representativo de los imaginarios e ideas sobre educación y autoridad política propios de la comunidad cultural y elite política chilena, en el contexto de consolidación del sistema republicano.

Palabras clave: Siglo XIX, Oratoria, Cultura Clásica, República Chilena, Educación Humanista, Andrés Bello, José Joaquín de Mora.

\section{ABSTRACT:}

Between April and July 1830, the enlightened elite of Chile witnessed a tough academic debate between the directors of the Liceo de Chile and the Colegio de Santiago, José Joaquín de Mora and Andrés Bello. This article seeks to analyze the discourses of this controversy in relation to the political and cultural context that framed it. The hypothesis suggests that, in addition to reflecting a partisan struggle, the concepts and topics developed in the debate offer a representative testimony of the imaginary and ideas about education and political authority of the cultural community and the Chilean political elite, in the context of consolidation of the republican system.

Keywords: 19th century, Oratory, Classical Culture, Chilean Republic, Humanist Education, Andrés Bello, José Joaquín de Mora.

Recibido: abril 2020

Aceptado: junio 2020

\footnotetext{
${ }^{1}$ Doctora en Historia, Pontificia Universidad Católica de Chile. Académica de la Facultad de Educación y Ciencias Sociales, Universidad Andrés Bello. mhuidobro@unab.cl. El presente artículo es resultado del proyecto de investigación FONDECYT Regular №1180056.
} 


\section{Introducción}

Entre los meses de abril y julio de 1830, la elite ilustrada y política de Valparaíso y Santiago de Chile fue espectadora de una singular polémica escrita entre dos de los principales líderes intelectuales de la época: el español José Joaquín de Mora y el venezolano Andrés Bello.

Ambos llevaban poco tiempo en Chile, si bien se conocían con anterioridad, habiendo colaborado en proyectos literarios durante sus estadías en Londres. Los dos habían desarrollado una labor intelectual y académica destacada, cuyas trayectorias eran reconocidas y admiradas por la comunidad letrada chilena. Ambos, finalmente, habían sido invitados por autoridades políticas de Chile a fines de la década de 1820, para aportar al proyecto de consolidación de la naciente república, en un contexto marcado por la polarización político partidista del país 2 .

El prestigio que ostentaban y sus vertiginosas carreras en Chile pronto los habilitaron para encabezar importantes proyectos educacionales, área particularmente sensible para fortalecer el proyecto republicano patriota. En enero de 1829 y bajo los auspicios del entonces presidente Francisco Antonio Pinto, Mora inauguró y asumió la dirección del Liceo de Chile, establecimiento que se propuso cubrir desde la educación elemental hasta los estudios superiores con una orientación liberal y científica.

Bello, por su parte, fue invitado a asumir, a comienzos de 1830, la dirección del Colegio de Santiago, proyecto impulsado por Diego Portales y por la elite conservadora de la capital, y que funcionaba desde marzo de 1829 con un equipo de profesores franceses traídos a Chile para esos efectos ${ }^{3}$.

De esta manera, hacia marzo de 1830, los roles de Bello y Mora, como líderes de los establecimientos escolares conservador y liberal, los ubicaban en veredas opuestas de un mismo escenario educacional, expresión, a su vez, del polarizado ambiente político. Y esto los conduciría inevitablemente a rivalizar.

Desde un comienzo, José Joaquín de Mora vio con recelo el surgimiento del Colegio de Santiago y criticó a su cuerpo de profesores franceses a través de El Mercurio de Valparaíso ${ }^{4}$. Sin embargo, la particular polémica entre ambos personajes se gestó a raíz de la publicación de la Oración inaugural del curso de oratoria del Liceo de Chile, pronunciada por Mora el 20 de abril de 1830.

\footnotetext{
2 Precedido de su fama como abogado y versificador neoclásico, José Joaquín de Mora llegó a Santiago en abril de 1828, con el cargo de Oficial Mayor auxiliar del Ministerio del Interior. Por su parte, Andrés Bello arribó a Chile en junio de 1829, como Oficial Mayor del Ministerio de Relaciones Exteriores. Jaksic, Iván. 2010. Andrés Bello: la pasión por el orden, Santiago, Universitaria, p. 135; Ávila M., Alamiro. 1982. Mora y Bello en Chile, Santiago, Ediciones de la Universidad de Chile, pp. 18-21.

3 Silva C., Raúl. 1965. Don Andrés Bello, 1781-1865, Santiago, Andrés Bello, p. 37; Amunátegui, Miguel Luis. 1888. Don José Joaquín de Mora. Apuntes biográficos, Santiago, Imprenta Nacional, pp. 201-202.

${ }^{4}$ Orrego V., Eugenio. 1953. Don Andrés Bello, Zigzag, Santiago, pp. 92-93; Silva C. 1965. Don Andrés Bello, p. 39.
} 
Aun tratándose de un discurso relativo a la importancia de la oratoria y a los contenidos curriculares del curso, sus palabras incluyeron críticas y ataques que, para muchos lectores, apuntaban al cuerpo docente del Colegio de Santiago. La respuesta no tardó en llegar. Mediante pronunciamientos publicados en el diario El Popular, una voz anónima -asociada a Bello- inició un cuestionamiento a la calidad del Liceo de Chile y a la de la oración inaugural proferida por Mora, abriéndose así una querella pública escrita y literaria. Esta incluyó las respuestas desde el Liceo de Chile en pasquines sueltos firmadas colectivamente por sus alumnos y la intromisión de una tercera voz que, desde El Mercurio de Valparaíso, asumió parcialmente la defensa del establecimiento y del discurso de Mora, así como la pretensión del veredicto de este debate.

Si bien la polémica atrajo la atención pública, dado el prestigio de sus protagonistas, sus asuntos de discusión fueron áridos y su especificidad llega a parecer fruto del simple afán por ostentar el bagaje cultural de los involucrados ${ }^{5}$. La calificación de las materias de debate como fastidiosas, pedantes y de escasa relevancia, así como la consideración de la participación de Bello como una situación insólita, si bien comprensible por el contexto político, son juicios que han primado en la historiografía 6 . Por eso, aun cuando los documentos referidos a la polémica han sido compilados como testimonio singular de las biografías de Mora y de Bello, la mayor parte de los estudios centrados en la labor intelectual de ambos no se ha detenido mayormente en el análisis de su contenido como objeto de estudio, sino solo en la descripción de sus principales momentos ${ }^{7}$.

No obstante, los argumentos, su fundamentación y su disposición forman parte de un interesante discurso que, más allá de su especialización, denota conceptos e imaginarios relativos a educación, política, ciudadanía y autoridad que circulaban entre la elite letrada y dirigente en el contexto de la consolidación del orden republicano en Chile.

En este sentido, en la oposición de ambos establecimientos y de sus líderes no solo es posible conocer un ejemplo concreto de la confrontación entre liberales y conservadores ${ }^{8}$. Nuestra hipótesis sugiere que, desde una perspectiva cultural, la polémica entre Bello y Mora, planteada como materia de opinión pública de alcance político, refleja las categorías y códigos a partir de los cuales la comunidad cultural letrada de Chile se legitimó, política y socialmente,

\footnotetext{
${ }^{5}$ Amunátegui, Miguel Luis. 1888. Don José Joaquín de Mora, p. 231; Amunátegui, Miguel Luis. 1882. Vida de Don Andrés Bello, Santiago, Pedro G. Ramírez, p. 335; Orrego V., Eugenio. 1953. Don Andrés Bello, p. 94.

${ }^{6}$ Jaksic, Iván. 2010. Andrés Bello, p. 136; Vidal, Santiago. 1982. Andrés Bello. Americanista y filósofo, Madrid, Oriens, p. 33; Ávila, Alamiro. 1982. Mora y Bello en Chile, p. 41.

7 Ávila, Alamiro. 1982. Mora y Bello en Chile, pp. 39-42; Jaksic, Iván. 2010. Andrés Bello, pp. 130-131; Amunátegui, Miguel Luis, Don José Joaquín de Mora, pp. 222-237; Sotomayor V., Ramón. 1875. Historia de Chile durante los cuarenta años transcurridos desde 1831 hasta 1871, Santiago, Imprenta de la Estrella de Chile, Tomo I, pp. 109-110. 8 En esa época, las polémicas literarias no eran extrañas y en ellas, muchas veces, es posible inferir sobreentendidos políticos. El mismo José Joaquín de Mora ya había sostenido una polémica contra Juan Nicolás Böhl de Faber, cuando publicaba el diario Crónica científica y literaria (1817-1820). Monguió, Luis. 1967. Don José Joaquín de Mora y el Perú del ochocientos, Madrid, Castalia, p. 7; Ávila, Alamiro. 1982. Mora y Bello en Chile, p. 19.
} 
mediante la construcción y validación de una noción del buen ciudadano al servicio de lo que la república requeriría. Si bien aparecen como antagonistas distantes, ambos intelectuales pueden considerarse, entonces, como miembros de una misma comunidad de interpretación, que compartía códigos y perspectivas que merecen revisarse con detención ${ }^{9}$.

El debate no era solo académico y pedagógico, sino también político, en su más profundo sentido. Los esfuerzos que le subyacen dan cuenta de una lucha por ganar o confirmar la autoridad intelectual y cultural de sus participantes, pues ella, en última instancia, daría garantía de poder político.

En este escenario, la instancia desde la que se generó la polémica -esto es, el curso de oratoria- adquiere también una especial significación. El debate mismo constituye una querella por una legitimación retórica, cuyo valor debe comprenderse en el marco del modelo educacional que los contendores, Mora y Bello, impulsaban. Uno que relevaba la importancia del arte de hablar, de la latinidad y de los estudios clásicos como condiciones de validación social y cultural, y que idealizaban la figura de Cicerón, el orador, como modelo del ciudadano republicano.

De esta manera, este artículo propone analizar las ideas referidas a educación y autoridad política contenidas en los discursos de la polémica entre Bello y Mora, como representaciones de un imaginario propio de la comunidad cultural a la que pertenecían. Para ello, será necesario revisar, primero, los antecedentes sobre los establecimientos que estos intelectuales dirigieron, así como sus propuestas educacionales y, luego, el contenido fundamental de la oración inaugural y de la polémica. Así será posible analizar los recursos argumentativos utilizados en el debate y las ideas sobre oratoria, ciudadanía y cultura que los sostenían, con el fin de reconstruir, mediante ellos, las nociones de educación y autoridad política en base a las cuales ambos contendores buscaron legitimarse.

\section{El Liceo de Chile y el Colegio de Santiago: antecedentes de una polémica}

La educación fue uno de los primeros ámbitos de interés de los intelectuales que lideraron el proceso independentista y la configuración republicana de Chile. Inspirados por un ideario ilustrado, personajes como Juan Egaña, Manuel de Salas y Camilo Henríquez, entre otros, eran firmes convencidos de que el orden político, la libertad y el ejercicio pleno de la soberanía se

\footnotetext{
${ }^{9}$ Precisamente, Peter Burke observa que la definición de una comunidad no supone homogeneidad. En su interior y en la determinación misma de sus alcances, subyacen tanto conflictos como solidaridad, y es por medio de ellos que se construye identidad y pertenencia. Burke, Peter, 2006. Lenguas y comunidades en la Europa moderna, Madrid, Akal, pp. 11-12.
} 
alcanzarían a través de la formación integral -moral, espiritual, física e intelectual- de los nuevos ciudadanos. La educación tenía, por tanto, un carácter y fundamento políticos ${ }^{10}$.

Por este motivo, el Instituto Nacional, primer establecimiento escolar republicano, fue creado tempranamente, en 1813 , y reabierto en 1819, una vez recuperado el gobierno patriota. A partir de entonces, surgieron diversas iniciativas para impulsar la creación de escuelas de primeras letras a lo largo del territorio chileno, que cubrieran la formación elemental de la población. Sin embargo, la falta de recursos y de profesores, en algunos casos, obstaculizaron el desarrollo de estos proyectos durante los primeros años de la república ${ }^{11}$. La educación secundaria, por su parte, tuvo escaso desarrollo, quedando concentrada en el Instituto Nacional $y$ en algunos seminarios en Santiago.

En ese contexto, la labor de intelectuales extranjeros llegados a Chile sería fundamental para dar impulso a nuevos proyectos educacionales, permitiendo que, a fines de 1830 , se contabilizaran once establecimientos secundarios en la capital. El Liceo de Chile y el Colegio de Santiago destacaron entre ellos ${ }^{12}$.

La llegada de José Joaquín de Mora y de su esposa, Fanny Delauneux, quien se ocuparía de abrir el primer colegio para mujeres, fue celebrada por muchos. El matrimonio contaba con experiencia en proyectos educacionales y recibió el apoyo de la elite santiaguina y del gobierno chileno para iniciar un nuevo proyecto en el país ${ }^{13}$. Por eso, con solo dos meses en Chile, pudieron anunciar la pronta apertura del Liceo de Chile y de la escuela femenina. El 12 de abril de 1828, el periódico La Clave incluía un aviso "Acerca de la casa de educación de hombres que se proyecta poner por un particular" ${ }^{14}$, por la que se esperaba ofrecer una formación preparatoria que dispusiera a los jóvenes para cursar futuras carreras que hicieran de ellos, buenos ciudadanos. El anuncio confirmaba así el rol que se esperaba de todo proyecto educacional: el de formar hombres de virtud para el bien de la comunidad política.

\footnotetext{
${ }^{10}$ Serrano, Sol; Ponce de León, Macarena; Rengifo, Francisca. 2013. Historia de la educación en Chile (1810-2010), Santiago, Taurus, Tomo I, pp. 61-63; Toro, Pablo. 2018. "Ideas políticas educacionales en Chile, c.1810-c.1980", en Jaksic, Iván y Gazmuri, Susana (ed.), Historia política de Chile, 1810-2010, Santiago, Fondo de Cultura Económica, Tomo IV, p. 108; Iglesias, Ricardo. 2009. "El papel de la educación en la construcción del estado nacional chileno en el siglo XIX", en Cid, G. y San Francisco, A., Nación y Nacionalismo en Chile. Siglo XIX, Santiago, Centro de Estudios Bicentenario, pp. 42-43.

${ }^{11}$ Aedo-Richmond, Ruth. 2000. La educación privada en Chile: un estudio histórico-analítico desde el periodo colonial hasta 1990, Santiago, Ril, p. 30.

12 Biblioteca Nacional de Chile, "Cuadro de las casas de educación para varones en esta capital", El Araucano n¹8, 15 de enero de 1831, p. 4. Labarca, Amanda. 1939. Historia de la enseñanza en Chile, Santiago, Imprenta Universitaria, pp. 83-84.

13 Ávila, Alamiro. 1982. Mora y Bello en Chile, p. 22; Subercaseaux, Bernardo. 1997. Historia de las ideas y de la cultura en Chile, Santiago, Universitaria, Tomo I, pp. 25-26; Stuardo, Carlos. 1950. El Liceo de Chile 1828-1831. Antecedentes para su historia, Santiago, Imprenta Universitaria, pp. 5-6.

${ }^{14}$ Biblioteca Nacional de Chile, La Clave n69, 12 de abril de 1828.
} 
La propuesta, desde un principio, comprendió un boceto para el plan de estudios preparatorios (secundarios), que daba un lugar primordial a las humanidades "en todos sus ramos": gramática latina, traducción y aplicación de autores clásicos del siglo de Augusto, historia romana basada en los estudios de Rollin, gramática castellana, retórica, poética, literatura castellana y lengua francesa. Agregaba, además y por primera vez, la enseñanza de historia antigua y moderna. Así, se ofrecía como una propuesta que mejoraba la del Instituto Nacional, que incluía cursos principales de latín, filosofía y matemáticas, y que, según un informe de Juan Egaña, hacia 1826, no había logrado ofrecer una formación de buena calidad ${ }^{15}$.

Los fundamentos de esta propuesta formativa habían sido publicados, días antes, en el prospecto de El Mercurio Chileno, periódico creado por José Joaquín de Mora. Reafirmando su convicción de que el objetivo de los estudios debía ser siempre la utilidad pública y que el ciudadano republicano, como parte integrante del Estado, debía ordenar sus facultades en favor de la felicidad común, Mora indicaba que los jóvenes debían formarse para pensar rectamente y para hablar con claridad y elegancia. Así justificaba la importancia de las humanidades, que se iniciaban con la enseñanza de la lengua y la gramática latinas como puertas al pensamiento y sabiduría de los autores clásicos y al ejemplo histórico de las civilizaciones antiguas. Sin su estudio, afirmaba Mora, cualquier otro conocimiento posterior quedaría mal amalgamado ${ }^{16}$.

Días antes de que el Liceo de Chile abriera sus puertas, el 16 de enero de 1829, circulaba su plan de estudios en detalle. El aprendizaje progresivo del latín se proyectaba desde el primer hasta el quinto año, suponiendo la enseñanza de gramática, la historia de los imperios antiguos, la lectura de autores clásicos, historia griega y romana y, finalmente, el análisis razonado de escritores selectos. Para eso, no se utilizaría la gramática de Nebrija, que tradicionalmente ocupaban otros establecimientos, como el Instituto Nacional, sino el manual elaborado por el mismo José Joaquín de Mora en su periodo londinense, lo que daba distinción a la propuesta pedagógica.

Mora lamentaba la escasa literatura local en Chile y consideraba como único medio de reparar esa falta, el implementar un sistema de estudios fundado en los modelos clásicos y en la literatura francesa moderna, para inspirar el buen gusto y el correcto razonamiento. El plan

\footnotetext{
${ }^{15}$ Según Domingo Amunátegui, Egaña había descrito en términos lamentables el estado de las cátedras de latinidad del Instituto Nacional: una elemental que no incorporaba la traducción de autores; otra que incluía solo la versión latina de las fábulas de Esopo, además de Quinto Curcio y quizás otro autor; y una de nivel superior que no se realizaba, por falta de estudiantes preparados. De todos modos, la calidad habría mejorado desde 1826, con el rectorado de Juan Francisco Meneses, basando los cursos en la gramática de Nebrija. Amunátegui, Domingo. 1889. Los primeros años del Instituto Nacional. 1813-1835, Santiago, Imprenta Cervantes, p. 382. Hanisch, Walter. 1991. EI latín en Chile, Santiago, Fondo Andrés Bello, p. 87.

${ }^{16}$ Colección Matta Vial, Biblioteca Nacional de Chile, "Educación”, El Mercurio Chileno. Prospecto, Santiago, 1 de abril de 1828, p. 37.
} 
proyectaba también la futura creación de un curso de oratoria con aprendizaje práctico, que habilitara a los estudiantes para debatir sobre política y derecho ${ }^{17}$.

El Liceo de Chile se propuso como un colegio privado, pero recibía financiamiento del Estado por medio de becas para los estudiantes, lo que, desde un comienzo, generó críticas por parte de algunos sectores, advirtiendo el menoscabo que implicaba para el Instituto Nacional ${ }^{18}$. Mora contaba con el apoyo del presidente Pinto, cuyas hijas se inscribieron en el colegio para señoritas que Fanny Delauneux inauguró en mayo de 1829.

Algunos anuncios que circularon en el diario La Clave hablaban de un inicio exitoso. El 19 de febrero de 1829, se anunciaba la incorporación del profesor Portés, llegado de Francia, para hacerse cargo de la cátedra de Filosofía, así como la apertura de un segundo curso de Latinidad $^{19}$. En marzo, circuló también un aviso que sugería a los padres de familia no encargar al extranjero los manuales de Gramática Latina, pues el texto redactado por Mora se reimprimiría pronto. El liceo estaba funcionando con el interés de la comunidad capitalina ${ }^{20}$.

No obstante, la suerte del establecimiento se vinculaba al quehacer político, el que, durante 1829, experimentaría importantes cambios. La reelección del presidente Francisco Antonio Pinto, quien había apoyado decididamente al proyecto de Mora, fue objeto de serias controversias que llevaron al mandatario a renunciar meses después. La derrota definitiva de los liberales se cerraría al año siguiente, en abril de 1830, con la victoria de los conservadores en la batalla de Lircay.

Junto con esto, el Liceo tuvo sus propias dificultades internas. Los profesores eran pocos: además de las clases de Mora, los franceses Portés y Clochard dictaban las de filosofía y de latín, mientras que Andrés Gorbea enseñaba matemáticas. Por eso, intentaron implementar el método de enseñanza mutua ${ }^{21}$. No obstante, el surgimiento temprano de un establecimiento rival dificultaría aún más su desarrollo.

Se trataba del Colegio de Santiago, cuyo proyecto también había comenzado a fraguarse en 1828, cuando el periodista francés Pierre Chapuis, con el apoyo de algunos conservadores liderados por Diego Portales, viajó a Europa para invitar a docentes galos a fundar un establecimiento de estudios secundarios y superiores en la capital chilena. La llegada de este

\footnotetext{
17 Plan de estudios del Liceo de Chile con algunos pormenores sobre su ejecución y sobre la disciplina del establecimiento, Santiago, Imprenta de R. Rengifo, 1 de enero de 1829.

18 Aedo-Richmond, Ruth. 2000. La educación privada en Chile, p. 36; Pérez, Rodrigo. 2011. "Los inicios de la enseñanza del Derecho Constitucional en el Chile decimonónico: el Liceo de Chile y el Colegio de Santiago (18281831)", en Anuario de Estudios Americanos, vol. 68, Madrid, pp. 146-147.

${ }^{19}$ Biblioteca Nacional de Chile, La Clave n85, 19 de febrero de 1829.

${ }^{20}$ Biblioteca Nacional de Chile, La Clave ${ }^{\circ} 86,5$ de marzo de 1829; $n^{\circ} 87,12$ de marzo de 1829; y $n^{\circ} 88,14$ de marzo de 1829.

${ }^{21}$ Ávila, Alamiro. 1982. Mora y Bello en Chile, p. 25.
} 
equipo en diciembre de 1828 permitió pronto elaborar y difundir un primer prospecto, que circuló en Santiago a comienzos de 1829 para anunciar su apertura en marzo del mismo año.

La estructura de los cursos distinguía un nivel elemental de dos años, uno de humanidades y bellas letras, y un área de ciencias. El primer caso incluía clases de historia sagrada, geografía, aritmética, escritura, dibujo y gramática latina. Esta última asignatura era la única que merecía una extensa y detallada explicación. Se esperaba que, al primer año, el estudiante conociera las declinaciones y conjugaciones para la traducción y lectura de frases de autores clásicos, y que luego, al segundo año, se dispusiera a la traducción de fragmentos de autores romanos, como Justino, Cornelio Nepote y las cartas familiares de Cicerón, las fábulas de Fedro y la obra Viris ilustribus Romae. Además, se iniciaba en el conocimiento de la mitología antigua y en las primeras clases de griego.

Estos cursos debían preparar a los estudiantes para el nivel de humanidades, que incluía la explicación de pasajes selectos de Quinto Curcio y Tito Livio, del De amicitia y De senectute de Cicerón, de las Bucólicas y Geórgicas de Virgilio, y de las Metamorfosis de Ovidio; y en una segunda etapa, fragmentos de Salustio, de Tácito, de las arengas de Cicerón, de la Eneida, de las Odas de Horacio, de los Diálogos de Luciano y la Ciropedia de Jenofonte. El griego también se profundizaba con la explicación de las fábulas de Esopo y del Nuevo Testamento, para luego pasar a fragmentos de la lliada.

El objetivo era que este recorrido culminara con los estudiantes listos para iniciarse en retórica, para lo cual se preparaban con ejercicios de composición en latín y castellano. Para dicho curso, el prospecto proponía una enseñanza explicativa sobre una selección de los discursos contenidos en historiadores antiguos, poetas latinos y trágicos griegos, las oraciones de Cicerón, las arengas de Demóstenes, el Ars poética de Horacio, la Eneida y la lliada, esperando la memorización de fragmentos que formaran el gusto de los alumnos a través de la observación de la belleza de los escritores grecorromanos ${ }^{22}$.

Otras asignaturas, igualmente, se cruzaban con el conocimiento de los clásicos: en filosofía, se consideraba a Aristóteles para la enseñanza de la lógica; en economía política, debía estudiarse a Platón y a Aristóteles como antecedentes; en derecho romano, se contemplaba la historia desde Rómulo hasta Justiniano; y se ofrecía una asignatura de historia antigua que abarcaría el mundo asirio, egipcio, griego y romano.

Si bien el establecimiento sería liderado, en un comienzo, por Pierre Chapuis, sus desavenencias acabaron por apartarlo del proyecto, encaminándolo al Liceo de Chile. La dirección del Colegio de Santiago quedó a cargo de Juan Francisco Meneses, quien, a su vez, había renunciado a la rectoría del Instituto Nacional, tras haber perdido parte del financiamiento y respaldo estatal en beneficio del proyecto de Mora.

22 Prospecto del Colegio de Santiago, Santiago, Imprenta Rengifo, 1829. 
El Colegio de Santiago inauguró sus actividades el 16 de marzo de 1829, con más de cien alumnos y con un discurso del rector Meneses, en el que confirmaba que la enseñanza científica no tendría sentido si no tuviera un fundamento moral: hacer ciudadanos virtuosos ${ }^{23}$. El mayor número de inscripciones los registraron los cursos de primeras letras y de latinidad, triplicando e incluso cuadruplicando el número de alumnos de asignaturas como botánica y física, humanidades, derecho, francés, dibujo y música ${ }^{24}$.

Para fines de 1829 y comienzos de 1830, los anuncios de los exámenes públicos del Liceo de Chile y los programas de los ejercicios literarios del Colegio de Santiago sugerían que ambos establecimientos lograban cerrar un primer año que podía dar relativa cuenta de los progresos de sus estudiantes. El Liceo de Chile indicaba que los exámenes de latinidad contemplarían la traducción, explicación y análisis de las Selectae e profanis scriptoribus y de las Epitome Historiae Sacrae ${ }^{25}$. En tanto, el Colegio de Santiago afirmaba que sus alumnos de Humanidades habían logrado leer a prosistas y poetas latinos, por lo que se les pediría que se abocaran a la traducción de las Catilinarias y las Églogas virgilianas, mientras que los de los cursos de gramática latina podrían traducir fragmentos de las Epitome Historiae Sacrae y de las fábulas de Fedro ${ }^{26}$. El quehacer académico de los dos establecimientos se mantenía, así, como objeto permanente de atención pública.

Dos avisos relevantes siguieron, además, a estas publicaciones. El del Liceo de Chile anunciaba un curso de oratoria que se iniciaría en el mes de marzo de 1830, basado en los mejores escritos de Cicerón, las Instituciones de Quintiliano y las obras de Rollin y Blair ${ }^{27}$.

El Prospecto del Colegio de Santiago de 1830 anunciaba, por su parte, que el rector Meneses había decidido dejar su cargo y que Andrés Bello asumiría la dirección del establecimiento ${ }^{28}$. El documento incluía también, en su propuesta curricular, un curso de Retórica basado en Cicerón, Horacio y Virgilio, si bien no indicaba cuándo comenzaría.

Hasta entonces, ambos habían seguido una propuesta formativa que, en su generalidad, era muy similar, pero que buscaba diferenciarse en su contenido y en sus metodologías pedagógicas, rivalizando por la autoridad académica que correspondía a cada uno. Y sería precisamente, en el contexto de una disputa académica, que se abriría una lucha cuyo trasfondo era también de naturaleza cultural, financiera y política.

\footnotetext{
${ }^{23}$ Biblioteca Nacional de Chile, "Instalación del nuevo colegio titulado de Santiago", Gaceta de Chile n¹6, 3 de abril de 1829.

${ }^{24}$ Ávila, Alamiro. 1982. Mora y Bello en Chile, p. 81.

25 Programa de los exámenes públicos: que han de celebrarse en el Liceo de Chile en los días 8, 9 y 11 de febrero de 1830, Santiago, Imprenta de R. Rengifo, 1830.

26 "Programa de los ejercicios literarios del colegio de Santiago", en Ávila, Alamiro. 1982. Mora y Bello en Chile, pp. 82-88.

27 Programa de los exámenes públicos: que han de celebrarse en el Liceo de Chile en los días 8, 9 y 11 de febrero de 1830, Santiago: Imprenta de R. Rengifo, 1830.

${ }^{28}$ Prospecto del Colejio de Santiago, Santiago, Imprenta de R. Rengifo, 2 de marzo de 1830.
} 


\section{La oración inaugural del curso de oratoria y el desarrollo de una polémica}

La rivalidad entre ambos establecimientos se había hecho evidente a lo largo de 1829, acusándose mutuamente de la mala formación que ofrecían y de falsear los resultados de sus estudiantes ${ }^{29}$. Bastaría solo una provocación más para que ello se transformase en abierta polémica. El contexto político recrudecía este ambiente: los conflictos entre liberales y conservadores acabaron en una guerra civil que se selló con la victoria conservadora en la batalla de Lircay, el 17 de abril de 1830.

Solo tres días después de ese acontecimiento, José Joaquín de Mora abría el curso de oratoria del Liceo de Chile con su oración inaugural, la que días después sería publicada, según indicaba la referencia impresa, por los alumnos de dicho establecimiento. El discurso se inicia con una reflexión acerca de la importancia del arte de hablar bien como un recurso elemental para la formación de ciudadanos al servicio de la utilidad de la patria y del bien de la humanidad. Dotado el ser humano de razón y de palabra, en esta última se hallaría la clave de la existencia de las sociedades, que radica en la comunicación. El fundamento lo hallaba Mora en el ejemplo de las repúblicas antiguas, cuya grandeza descansaba en la voz de sus oradores. Cicerón, entre todos, se erigía como voz de autoridad y símbolo de la oratoria.

No obstante, afirmaba Mora, el don de la palabra en Chile se había corrompido desde los tiempos del dominio colonial español y las reformas de los Habsburgo, encontrándose dañada por el vulgarismo y los extranjerismos. De ahí que, en su opinión, resultaba peligrosa la influencia que podía ejercer "la superficialidad exportada de más allá de los Pirineos, la preferencia de las trivialidades modernas a expensas de los primores elevados de la literatura clásica" ${ }^{30}$, que amenazaban con hacer de la lengua castellana, "servil imitadora de escritores extraños, y órgano venal de los libreros del Sena y del Garona" ${ }^{31}$. Por eso, hacía un llamado a la juventud para evitar someter su educación al "yugo de algún pedante ultramarino" ${ }^{32}$, que ni siquiera manejaría la lengua que pretendería enseñar. Su crítica se cerraba, finalmente, con una alusión a Cicerón y a su discurso Pro Flacco, para continuar luego con su propuesta pedagógica, basada en el ejemplo de los antiguos.

Sin aludir de manera explícita a los docentes del Colegio de Santiago, Mora hacía referencia evidente a la cultura francesa y así lo entendieron los profesores liderados por Andrés Bello, quienes se sintieron directamente atacados. La primera respuesta, que se publicó de forma

\footnotetext{
${ }^{29}$ La tensión se había manifestado desde la llegada de los profesores franceses encabezados por Chapuis, quienes fueron criticados en periódicos liberales como El Centinela, El avisador de Valparaíso y El Crisol.

${ }^{30}$ Oración inaugural del curso de Oratoria del Liceo de Chile, pronunciada el día 20 de abril de 1830 por D. José Joaquín de Mora, director de aquel establecimiento. Le dan a luz los alumnos, Santiago, Imprenta de R. Rengifo, 1830, p. 6. 31 Ídem.

32 Ídem.
} 
anónima en el periódico El Popular del 13 de mayo de 1830, se dirigió abiertamente contra el Liceo de Chile y su rector, tanto en términos de la calidad del establecimiento como del contenido literario y gramatical de la oración inaugural.

Si bien no se trataba ya de un discurso, la disposición de la respuesta la instala como tal, abriendo una polémica retórica que parece evocar el estilo ciceroniano de las Catilinarias. Se inicia con una invectio al estilo de las célebres palabras del orador romano, quosque tandem abutere, catilina (Catil. I.1), al cuestionar la calidad moral del Liceo de Chile y de su rector, decidiendo que había llegado el momento de poner freno a sus errores y abusos:

"Este establecimiento, se decía, es una casa de desorden, sin disciplina, sin método fijo, sin profesores. Lejos de corresponder a las intenciones con que se planteó, no es ya más que una carga estéril para el país, y un escándalo a que debe ponerse fin (...) Este momento ha llegado: podemos hablar con franqueza y claridad, porque nuestro juicio reposará sobre la base de los hechos, y denunciando los abusos no temeremos ya que se nos tache de detractores injustos, cuando no hacemos otra cosa que seguir el impulso de nuestros sentimientos en favor del país"33.

Al igual que Mora en su oración, el autor de la respuesta se presenta también como un ciudadano con el deber de defender los intereses de la patria, tal como correspondería, igualmente, a un buen orador. Desde allí, la discusión se tensará en una lucha por arrogarse la legitimidad de dicho rol, basándose, para ello, en una argumentación de tres órdenes que se reiteran a lo largo de toda la polémica: argumentos ad hominem o contra la calidad moral del interlocutor, razones gramaticales y tópicos culturales, todos orientados a desprestigiar al oponente.

Los argumentos ad hominem dominan en la primera contestación del 13 de mayo, centrándose en la acusación a Mora de haber abandonado sus deberes de educador, de lo que se derivaba, en el fondo, un abandono del deber del buen ciudadano por motivaciones partidistas. Las pruebas descansarían en la mala gestión y educación impartida en el Liceo de Chile, del que habría desertado una parte importante del alumnado, y en el cuestionable manejo de los recursos económicos otorgados por el Estado.

Dicha contestación se extendería en un segundo texto también titulado "Liceo de Chile", publicado en El Popular el 22 de mayo de 1830, en el que su anónimo autor pasaba a la argumentación gramatical e histórico-cultural. En el primer caso, las acusaciones apuntaban al mismo Mora como corruptor de la lengua castellana, criticando sus neologismos y los usos lingüísticos y léxicos que daba a algunas palabras en su discurso.

${ }^{33}$ Biblioteca Nacional de Chile, “Liceo de Chile", El Popular n8, 13 de mayo de 1830. 
En el segundo caso, el autor cuestionaba los conocimientos de Mora sobre ciertos personajes del mundo antiguo mencionados en su oración, acusándolo de ignorancia histórica. Los tópicos, en este ámbito, referían a la influencia de Isócrates y Demóstenes como oradores en el devenir de Grecia, la consideración de Ciro como un hombre prudente, y el lugar de Calidio en la historia de la retórica romana, habiéndolo puesto Mora al mismo nivel que a Cicerón.

Estos argumentos constituyeron el eje del debate. Tres réplicas y una fe de erratas, firmadas de manera colectiva por "Los alumnos de oratoria del Liceo" y luego por "Los comentadores", se difundieron en reacción a los artículos del Popular ${ }^{34}$. Los apoyaba también un autor anónimo -podría inferirse como más cercano a Mora- que desde El Mercurio de Valparaíso denunciaba también las falencias del Colegio de Santiago y advertía los peligros que una lucha partidista en el mundo de la educación podían generar para el bien público ${ }^{35}$. En respuesta, dos nuevas dúplicas tituladas como "Liceo de Chile" en El Popular ${ }^{36}$, más una a las columnas del Mercurio ${ }^{37}$, una editorial del Popular ${ }^{38}$, una sátira contra la ignorancia del autor del Mercurio ${ }^{39}$ y una carta de Andrés Bello señalando que su participación se limitó a la colaboración de apuntes literarios ${ }^{40}$, completaron la polémica.

Desde la primera réplica, los argumentos se ordenaron por los tópicos mencionados. Para el debate gramatical, se apoyan en ejemplos extraídos de la autoridad de los escritores castellanos, dando gala de sus conocimientos en la materia. Para la discusión histórico cultural, discurren en la citación de autores clásicos del mundo griego y romano, recurriendo además a la historiografía moderna, especialmente francesa.

El debate en torno a la prudencia de Ciro se basa en la Ciropedia y la Anábasis de Jenofonte, las Leyes de Platón, la Historia de Heródoto, las obras de Ctesias, Diodoro de Sicilia, Justino citado en latín-, Valerio Máximo, Flavio Josefo, Cicerón y en los historiadores modernos Rollin, Freret, Millot, Laharpe y Condillac. El referido a Isócrates se fundamenta en las cartas del mismo orador y en Plutarco. Respecto a la autoridad de Calidio, las citas latinas y traducidas de Cicerón,

\footnotetext{
${ }^{34}$ Biblioteca Nacional de Chile, "Comentario a un artículo del Popular", Santiago, Imprenta Republicana, 24 de mayo de 1830; "Comentario a otro artículo del Popular", Santiago, Imprenta Republicana, 1 de junio de 1830; "Nuevo comentario al Popular", Santiago, Imprenta Republicana, 23 de junio de 1830; "Fe de erratas al comentario de otro artículo del Popular", Santiago, Imprenta Republicana, 2 de junio de 1830.

${ }^{35}$ Biblioteca Nacional de Chile, "Paráfrasis", El Mercurio n69, Valparaíso, 21 de mayo de 1830; "Crítica”, El Mercurio $n^{\circ} 78$, Valparaíso, 4 de junio de 1830; "Al editor del Popular" y "A nuestros lectores de Santiago, excepto al ignorante editor del Popular", El Mercurio n93, Valparaíso, 23 de junio de 1830; "Crítica de D. Andrés Bello, sobre la Oración inaugural del Curso de Oratoria del Liceo de Chile", El Mercurio n98, Valparaíso, 30 de junio de 1830.

36 Biblioteca Nacional de Chile, "Liceo de Chile (III)", El Popular n¹0, 29 de mayo de 1830; "Liceo de Chile (IV)", EI Popular, 19 de junio de 1830.

37 "Al autor de los artículos del Mercurio de Valparaíso relativos al Colegio de Santiago", El Popular n¹1, 5 de junio de 1830 .

${ }^{38}$ Biblioteca Nacional de Chile, El Popular n¹5, 10 de julio de 1830.

39 Biblioteca Nacional de Chile, "Importante", El Popular n¹5, 10 de julio de 1830.

${ }^{40}$ Biblioteca Nacional de Chile, "Remitido", El Popular n¹5, 10 de julio de 1830.
} 
sobre todo de su obra Brutus, que versa precisamente sobre una descripción de las cualidades de todos los oradores romanos, sustentan el debate. Lo complementan, además, referencias a Quintiliano, Julio César, Dion Casio, al Diálogo de los Oradores atribuido a Tácito, y al moderno Bouillet.

El despliegue de citas y referencias da cuenta del bagaje cultural de los polemistas, que no se queda solo en la repetición de afirmaciones, sino en el análisis e interpretación de sus fuentes. La especificidad del debate, al parecer, no marginó a la comunidad de lectores, que siguió con atención su desarrollo. Entre sus impactos, se cuenta el desafío de los estudiantes del Liceo de Chile a sus pares de otros establecimientos para enfrentarse en exámenes académicos públicos y el intento de los alumnos del Instituto Nacional por aceptar el duelo, si no fuese por la intervención de José Joaquín de Mora para evitar su realización. En el fondo, las mismas comunidades habían sentido un llamado a defender su honor, en una polémica que trascendía a sus aspectos academicistas.

Del mismo modo, el autor de las columnas de El Mercurio sentiría la necesidad de dar su veredicto, juzgando a Mora como vencedor en la discusión relativa a Ciro, y a Bello como ganador en las relacionadas con Isócrates y Calidio. Con todo, reconocía la calidad de la oración inaugural del director del Liceo de Chile y criticaba el afán de figuras académicas de su nivel por desprestigiarse mutuamente.

Aunque la polémica concluyó a comienzos de julio de 1830, la rivalidad entre ambos establecimientos, señal de las diferencias entre los líderes que encabezaban ambos proyectos, no concluiría ahí. "Muchas plumas se convirtieron en puñales" ${ }^{41}$, afirma Amunátegui. En mayo de 1830, el gobierno, por mediación de Diego Portales, había iniciado una investigación sobre el Liceo de Chile, determinando el traspaso de las becas otorgadas al establecimiento de Mora para el Instituto Nacional ${ }^{42}$. El Liceo de Chile sabía que debería cerrar para el año siguiente y aun cuando subsistió hasta 1831, bajo la dirección de Juan de Quezada ${ }^{43}$, la pérdida de dichos apoyos económicos aceleró su final. No se trataría solo del desenlace del proyecto educacional, sino también de la participación de José Joaquín de Mora en Chile, quien se vería obligado a dejar el país en febrero de 1831.

\section{El rol de la oratoria y la autoridad del orador}

El afán de los polemistas en el debate sugiere que la batalla escrita trascendía su condición erudita y académica. Aquello que estaba en cuestión tampoco consistía en un asunto de egos ni se quedaba en la defensa del honor. La contienda era, fundamentalmente, un

\footnotetext{
${ }^{41}$ Amunátegui, Miguel Luis. 1888. Don José Joaquín de Mora, p. 213.

42 Congreso de Plenipotenciarios, sesión 33, 1 de junio de 1830, Sesiones de los Cuerpos Lejislativos de la República de Chile, Tomo XVIII, p. 344.

${ }^{43}$ Biblioteca Nacional de Chile El Araucano n³3, 30 de abril de 1831.
} 
enfrentamiento movido por una causa de autoridad política enmarcada en un asunto de legitimidad moral y cultural frente a la comunidad letrada y elite política de Santiago y Valparaíso.

Desde esa perspectiva, el motivo mismo de la polémica, es decir, un discurso relativo al arte de la oratoria con sus consecuentes respuestas, similares en tono, forma y fondo, ofrecen claves de inteligibilidad para comprender la vinculación entre educación, cultura y política en el imaginario de la élite ilustrada de Chile hacia 1830.

Es muy probable que la importancia que Mora confiere a la oratoria en su discurso, y de la que Bello se hace eco, se sustentase en sus propias experiencias educativas y lectoras. Tal como se desprende de la oración inaugural y de los textos siguientes, su concepción sobre el rol y valor de la oratoria se basaba en el modelo clásico antiguo, sobre todo romano y en particular ciceroniano, así como en el sentido que esta disciplina adquiría en un contexto de formación republicana.

Para la tradición platónica-ciceroniana, la oratoria no se concebía solo como la disciplina del hablar bien y bellamente. Razón y palabra, el estudio de la moral y el arte del habla constituían las bases para una educación de excelencia ${ }^{44}$. La importancia de la oratoria se fundaba en su vinculación a la filosofía y en su proyección política ciudadana. Desde este enfoque, el poder de la persuasión podía jugar un papel esencial en el camino de las sociedades hacia la civilización.

Siguiendo los planteamientos de Platón en Fedro y Gorgias, Cicerón sostuvo en todos sus tratados retóricos mayores -De oratore, Brutus y Orator- que la capacidad retórica no debía concebirse solamente como ars, sino como virtus, suma de pensamiento y palabra, verdad y belleza. Del orador debía esperarse sabiduría y rectitud, cuyo ejercicio podría cumplir a cabalidad en su correcto desempeño público ${ }^{45}$. Por este motivo, la filosofía debía constituir la base de la formación oratoria, pues solo así sería posible garantizar la rectitud moral del orador $^{46}$.

Esta es, precisamente, la noción que presenta Mora en su oración inaugural, pues centra su atención en el rol político del orador, así como en el carácter social y filosófico de la oratoria como herramienta que permitiría la asociación de los miembros de una comunidad:

"Este instrumento precioso, único intérprete de los pensamientos elevados, de los afectos puros, de los descubrimientos útiles, es el arte de hablar bien (...) Suprimid esta facultad del catálogo de las que nos caracterizan y no solo no concebiréis la posibilidad de dar leyes, de hacer descubrimientos, de satisfacer las primeras necesidades de la vida, sino que ni aún

\footnotetext{
${ }^{44}$ Grube, George. 1962. "Educational, rethorical, and literary theory in Cicero", en Phoenix, vol. 16, n4, Toronto, pp. 235-237.

45 Codoñer, Carmen. 1984. "Eloquentia y orator", Estudios Clásicos, n88, Madrid, p. 298; Kapust, Daniel. 2012. "Cicerón: el decorum y la moralidad de la retórica", en Praxis filosófica, n³5, Cali, pp. 263-265.

${ }^{46}$ Alberte G., Antonio. 1987. Cicerón ante la retórica, Valladolid, Universidad de Valladolid, pp. 15 y 20.
} 
podréis entender la existencia misma de la sociedad, el pacto que la forma, la comunicación de trabajos que la conserva" ${ }^{47}$.

El fundamento, afirmaba Mora, podría hallarse en el ejemplo histórico de las grandes civilizaciones, en particular, la romana: "Recorred los anales de vuestra especie y notad las épocas de su verdadera gloria. Siempre las distinguiréis, al través de las tinieblas de la historia, por la exactitud y por el esplendor del lenguaje" ${ }^{48}$.

La oratoria se concebía, entonces, como una herramienta política que podría ordenarse al servicio de la república. Esto adquiría especial importancia en el contexto de un Chile en vías de consolidar un sistema gubernamental y de participación política que, en oposición a los tiempos coloniales de la monarquía, garantizara la soberanía del país y la libertad de sus miembros.

El mismo Cicerón había hecho hincapié en la relación necesaria entre oratoria y democracia, reconociendo el origen de esta disciplina en la Grecia antigua, posterior a los tiempos de las tiranías (Bruto 12). Su desarrollo sería posible al alero del derecho y de los sistemas de libre participación política, pues requeriría de un marco normativo y cultural que se abriera al discurso público sin la coacción directa de un determinado poder ${ }^{49}$. Así, en el contexto de la naciente república chilena, la oratoria podía concebirse como un medio relevante, en especial, para la comunidad letrada que lideraría sus procesos políticos.

El orador también se dispondría en función de este bien. Cicerón, a ojos de Mora, encarnaría al arquetipo ideal, y por este motivo, parece intentar identificarse con su modelo romano. En este sentido, el esfuerzo de Mora por explicar las virtudes de la oratoria y del orador a través de este discurso no respondería solo a una razón académica orientada a explicar el programa de estudio. Esta cuasi apología de la disciplina ofrece una representación del orador como vir sapiens et bonus, lo que, en el contexto chileno, constituía una representación del hombre patriota y del ciudadano republicano, recurso que serviría a la legitimidad cultural y política que tanto Mora como Bello reclamaban para sí mismos.

Una batalla basada en la palabra podía ser también una batalla por la autoridad cultural y por el poder político. Cedant ama togae o "que las armas cedan a la toga" (De off. I.77), había dicho Cicerón en circunstancias de una guerra civil, validando el lugar del orador en la cima del sistema republicano: "que queremos sea autor del consejo público, caudillo en el gobierno de la ciudad, y el primero por su elocuencia y sabiduría en el Senado, en el pueblo y en las causas públicas" (De orat. III.65).

La lucha por defenderse desde la condición de oradores y maestros de oratoria por parte de Mora y Bello se aproxima, de esta manera, a la tradición latina y ciceroniana. En tiempos

\footnotetext{
${ }^{47}$ Oración inaugural del curso de oratoria del Liceo de Chile, pp. 1-2.

48 Oración inaugural del curso de oratoria del Liceo de Chile, p. 11.

49 López E., Antonio. 2000. Esencia y objeto de la retórica, Salamanca, Ediciones Universidad de Salamanca, p. 12.
} 
republicanos antiguos, el discurso público constituyó el género emblemático de la vida cívica romana. Por eso, su formación y ejercicio no estaban destinados a cualquiera, sino que eran reservados a una élite ${ }^{50}$. El orador debía asumir un rol ejemplar frente a la ciudadanía, representando simbólicamente la voz de la res publica, así como los valores que la definían libertad, civilidad, jurisprudencia, identidad cultural- que debían ser defendidos contra cualquier potencial amenaza ${ }^{51}$. Dice Cicerón: "en la moderación y sabiduría de un perfecto orador estriba no solo su propia dignidad, sino la de otros muchos particulares, y la salvación de toda la república" (De orat. I.34). Y así lo confirmaba Mora: "Un orador es el órgano vivo, el intérprete desinteresado, el sagrado depósito de la verdad y de la razón" 52.

Eso diferenciaba al orador frente al rétor. El primero, formado en escuelas filosóficas, debía distinguirse por su cultura universal, su dominio de los recursos literarios y científicos, su afán en la búsqueda de la verdad, su justo actuar y su palabra honesta ${ }^{53}$. Por eso, la oratoria era una disciplina que solo podría inculcarse luego de una formación en otros conocimientos previos, tal como lo planearon en sus respectivos currículos, el Liceo de Chile y el Colegio de Santiago, si bien ambos se atacaron con el cuestionamiento recíproco sobre el orden que seguía el plan de estudios de su adversario ${ }^{54}$.

El rétor, en cambio, sería aquel que se restringe al dominio de la palabra a través del estudio de tratados y normativas retóricas, utilizando esta destreza de acuerdo con la opinión sobre la que quisiera persuadir a su audiencia y no necesariamente para el bien común o la verdad. Así explicaba Mora los peligros de este segundo personaje: "Figuraos en el hombre elocuente un ingenio torcido y falso, un alma corrompida y viciosa, y tanto valdría, dice Cicerón, poner una arma mortífera en manos de un mancebo aturdido y destructor" ${ }^{55}$.

José Joaquín de Mora se cuida de establecer esta diferencia entre el orador y el retórico. Aun cuando en su oración inaugural habla sobre la necesidad de enseñar Gramática, previene que esta no consiste en una colección de reglas, a la que menosprecia, sino en el desarrollo de

\footnotetext{
50 Bloomer, W. Martin. 2011. The school of Rome, California, University of California Press, p. 194.

51 Dugan, John. 2009. "Rhetoric and the Roman Republic", en Erik Gunderson (ed.), The Cambridge Companion to Ancient Rhetoric, Cambridge, Cambridge University Press, pp. 183-185; Bernard, Jacques-Emmanuel. 2008. "Rhétorique et société chez Cicéron", Modèles linguistiques, n58, Lille, p. 49.

52 Biblioteca Nacional de Chile, Oración inaugural del curso de oratoria del Liceo de Chile, p. 13.

${ }^{53}$ Alberte G., Antonio. 1987. Cicerón ante la retórica, pp. 49-50.

${ }^{54}$ Biblioteca Nacional de Chile, "Liceo de Chile", El Popular n8, 13 de mayo de 1830; "Paráfrasis", El Mercurio n69, Valparaíso, 21 de mayo de 1830; "Al autor de los artículos del Mercurio de Valparaíso relativos al Colegio de Santiago", El Popular n¹1, 5 de junio de 1830.

${ }_{55}$ Oración inaugural del curso de oratoria del Liceo de Chile, p. 13. En efecto, decía Cicerón: "si al que carece de estas virtudes le damos la facilidad y abundancia en el decir, no haremos de él un orador, sino que pondremos un arma en manos de un loco furioso (De orat. III.55). Alberte G., Antonio. 1987. Cicerón ante la retórica, p. 25; Michel, Alain. 2003. Les rapports de la rhétorique et de la philosophie dans l'oeuvre de Cicéron, Leuven, Éditions Peeters, pp. 8183.
} 
la capacidad de descifrar los misterios del pensamiento y armonizarlos con la palabra. Así, se plegaba a los cuestionamientos a la retórica que también formaron parte de una tradición crítico-literaria hacia el mal orador, sobre todo cuando se trataba de un maestro que podría influir negativamente sobre sus discípulos. Son invectivas que Platón realiza en Gorgias (456a y ss.) y Fedro (266d) contra la retórica sofística y que luego Cicerón desarrolló en De oratore (I.84 y III.75-76) ${ }^{56}$. El móvil tras estas críticas sería moral y político. El orador o el responsable de su formación debían regirse por principios éticos, dado el impacto que podrían tener en la ciudadanía (De orat. III.55).

Cicerón asoció esta condición negativa a los graeculi o sofistas griegos (De orat. I.102 y I. 221), rescatando la superioridad del latín ${ }^{57}$. No se trataba de un menosprecio hacia la cultura griega o hacia sus sabios y oradores, sino hacia aquellos que representaban, para él, a los rétores sin formación filosófica. Por ende, no lo movía tanto una defensa abierta del latín o de su patria, sino un ataque a la oratoria mal entendida, que veía él encarnada en ciertos personajes extranjeros ${ }^{58}$.

Las críticas de Mora hacia el profesorado francés del Colegio de Santiago también merecen una segunda lectura desde esa perspectiva. Si bien su motivación evidente debió ser la amenaza que sentía desde la competencia directa a su proyecto, el contexto discursivo y la tradición literaria en los que enmarca su invectiva pudieron permitirle fortalecer su mensaje. El peligro que Mora advierte en sus oponentes consistiría en el riesgo de que deformen la lengua castellana y que promuevan su corrupción. Sin embargo, previene subliminalmente sobre un peligro cultural y político, por el riesgo de dejar a la juventud de Chile en manos inadecuadas, que solo se moverían por intereses particulares y partidistas.

Mora compara, precisamente, a los "pedantes ultramarinos" con los sofistas a los que despreciaba su referente romano: "y que semejante al sofista de quien habla Cicerón, restituye los alumnos al hogar paterno doblemente más estúpidos que cuando vinieron a sus manos" 59 . El problema que anotaba era trascendente a los resultados pedagógicos, pues bajo ellos latería una amenaza al patrimonio cultural del país y a las garantías de su asociación virtuosa:

"La lengua nacional es uno de los más preciosos elementos de ese ser moral, que, con el nombre de patria, inspira tantas acciones sublimes, y conserva en las reuniones de hombres

\footnotetext{
${ }^{56}$ La crítica, por lo general, apunta, en las voces de Sócrates y Craso, a la pretensión del rétor de ser un orador elocuente sin contar con el dominio científico y filosófico necesario. En esto estribaría la diferencia entre tener una capacidad técnica para hablar bien, la loquacitas, y ser un orator eloquens et sapiens. De orat. I.105; Alberte G., Antonio. 1987. Cicerón ante la retórica, p. 27; Tonti, Silvia. 1999. "La crítica del Gorgias a la retórica sofística y su relación con la primera definición de sofista en el diálogo homónimo", en Synthesis, n6, La Plata, pp. 121-122.

${ }^{57}$ Alberte G., Antonio. 1987. Cicerón ante la retórica, p. 30.

58 Alberte G., Antonio. 1987. Cicerón ante la retórica, p. 31; Grube, George. 1982. "Educational, rethorical, and literary theory in Cicero", p. 236.

${ }^{59}$ Oración inaugural del curso de oratoria del Liceo de Chile, p. 6.
} 
los intereses más sagrados y los lazos más íntimos. La culpable negligencia con que se abandona a las invasiones de la codicia, y a la sorda mina de la vulgaridad, ¿no es un desprecio de lo que nos honra, una abdicación de lo que nos engrandece, y la destrucción de toda esperanza de adelantamiento intelectual?" ${ }^{60}$.

Las respuestas que recibe desde el diario El Popular se orientan en una dirección similar. Los códigos de la contienda son los mismos, pues derivan de la misma tradición, aunque se ordenen en direcciones opuestas. Si bien se plantean como cuestionamientos técnicos, estos apuntan, en el fondo, a la deslegitimación moral de Mora como orador, luego como maestro o conductor de la juventud y, finalmente, como ciudadano. Se le acusa de manipular la verdad; de prometerlo todo y de no cumplir; de pasar de la calidad que se esperaba de él como profesor y como filósofo a la de folletista partidario y mezquino, categoría quizás cercana a la de los antiguos sofistas:

"El señor Mora sin intimidarse por el peso de la carga que se le propone, arrastrado sin duda por el celo del bien público o la convicción de la superioridad de sus fuerzas, acepta con facilidad, lo promete todo, se hace cargo de todo (...) Comenzaban a nacer luchas políticas en el país, y en el momento mismo en que se debió creer que el señor Mora estaba sin duda ocupado en el seno de su Liceo (...) deja a un lado la augusta misión que había tomado sobre sí para tomar el frívolo y fácil oficio de folletista, y dejando desde entonces de ser el hombre de la nación, se convirtió en creatura de una facción" ${ }^{61}$.

Se le acusa, luego, de ser él un corruptor de la lengua castellana y de no saber debatir, de pretender ser un literato y un profesor de elocuencia, sin serlo en estricto sentido. Lejos de tener la dignidad de un orador, sería un charlatán e ignorante impulsivo, quizás irracional, que, en lugar de validarse desde la calidad de su discurso, solo se dedicaba a denostar a los demás. $Y$ todo se vería reflejado en su oración, rebajada por sus contendores a la calidad de folleto:

"Nos será muy fácil probar que el mismo que echa en cara a los autores modernos la decadencia de la literatura española, es uno de los principales corruptores del gusto por sus neologismos, por la hinchazón y algarabía de su estilo (...) ¿A quién no llenarán de indignación las injurias que vomita contra unos establecimientos rivales? La única arma permitida en las contiendas literarias es el buen suceso (...) ¿Pero ese juez severo, ese defensor de las letras es digno de defender su causa? Una ojeada sobre aquel folleto probará lo contrario. Entremos ya en el examen de esa obra preciosa, triste testimonio de la completa ignorancia del autor en las materias que trata, y aun en su lengua nativa" ${ }^{62}$.

\footnotetext{
60 Oración inaugural del curso de oratoria del Liceo de Chile, p. 7.

61 Biblioteca Nacional de Chile, "Liceo de Chile (I)", El Popular n8, 13 de mayo de 1830.

${ }^{62}$ Biblioteca Nacional de Chile, "Liceo de Chile (II)", El Popular n9, 22 de mayo de 1830.
} 
Cerraba esta dura crítica la advertencia sobre la gravedad de sus faltas, la que radicaba, precisamente, en el hecho de que se tratase de un educador y de quien decía saber de oratoria. Otra vez, el comentarista asociado a Bello hacía ver que el problema de fondo era moral y político y, por esta razón, debía ser atendido por el mismo gobierno:

"Nos hemos dedicado particularmente a notar las impropiedades de lenguaje porque es vergonzoso para el jefe de un establecimiento de educación cometerlas tan graves, y doblemente vergonzoso para un profesor de elocuencia (...) Hemos creído llenar los deberes de buenos ciudadanos denunciando al público un escándalo que ya es tiempo de atajar. Lo demás pertenece a un gobierno celoso del bien público, y protector de la verdadera instrucción" ${ }^{63}$.

La disputa política se hace evidente en las últimas líneas. En el imaginario de esta comunidad letrada, los roles del educador, del orador, del ciudadano y del líder político se entrelazan para adquirir pleno sentido. Su vocación es común: consiste en su contribución al bien de la república. La batalla por arrogarse la calidad de buen orador implicaba la de aquella por ser buen ciudadano y la de validarse como tal ante la opinión pública, la elite ilustrada y el país. En otras palabras, es un enfrentamiento por ganar autoridad a través de la escritura y de la palabra.

En la Roma republicana definida por Cicerón, la auctoritas de los personajes públicos resultaba del encuentro de habilidad política, capacidad retórica y la fuerza de la persuasión ${ }^{64}$. La oratoria se concebía en sí misma como un espacio de batalla, si no en acción, sí de palabra ${ }^{65}$.

La polémica parece hacerse eco de ello. El demostrar un dominio cultural, al nivel de un filósofo, expresado en una sólida manifestación retórica, era condición necesaria para la distinción de un buen maestro, capaz de liderar un establecimiento educativo y, en último término, a la juventud que se formaba en él. Bagaje cultural y capacidad oratoria constituían una garantía de autoridad. Y dado que la educación se concebía como un medio indispensable para formar a los futuros ciudadanos que liderarían el proyecto republicano, el alcanzar dicha autoridad no representaba simplemente una validación en el medio ilustrado, sino también una legitimación política, a partir de la cual se alcanzaba, finalmente, el poder.

\section{Latinidad, clasicismo y las luchas por la legitimidad}

Tal como se ha establecido, la calidad del orador y la autoridad del maestro no pasaban únicamente por la demostración de su solidez retórica. Ella debía sustentarse en el manejo de

\footnotetext{
${ }^{63}$ Biblioteca Nacional de Chile, "Liceo de Chile (II)", El Popular n9, 22 de mayo de 1830. Una crítica similar se reiterará en la editorial de El Popular n ${ }^{\circ} 15,10$ de julio de 1830.

${ }^{64}$ Bernard, Jacques-Emmanuel. 2008. "Rhétorique et société chez Cicéron", p. 49.

65 Michel, Alain. 2003. Les rapports de la rhétorique et de la philosophie dans l'oeuvre de Cicéron, p. 21.
} 
conocimientos derivados del bagaje cultural del orador, de los cuales debía dar cuenta por medio de sus discursos. De ahí la relevancia de los contenidos mismos del debate, cuyo desarrollo, pese a que podría parecer ostentación o pedantería, resultaba esencial en una batalla por la legitimidad cultural y la autoridad política de los contendores.

Desde esta perspectiva, el hecho de que gran parte de los asuntos debatidos se haya concentrado en tópicos relativos al mundo clásico antiguo y, en particular, en la calificación de ciertos personajes como buenos oradores y prudentes gobernantes, tampoco parece circunstancial. Considerando que el currículum educacional de la élite, hasta comienzos del siglo XIX, daba particular relevancia al estudio de los clásicos, sobre todo latinos -tal como se evidencia en los planes de estudio de los establecimientos de Mora y Bello- el demostrar conocimientos históricos sobre la antigüedad y la lectura de sus principales autores debía resultar crucial en la polémica.

Su dominio suponía una doble carga simbólica. Por una parte, los estudios clásicos formaban al ciudadano político y dicho ciudadano era el hombre de elite. El conocimiento de la lengua latina y de su literatura confería prestigio social y cultural, pues devenía de un proceso educativo propio de las comunidades ilustradas ${ }^{66}$. Se trataba, así, de un elemento de distinción cultural, un vínculo de adhesión y pertenencia, así como una garantía de reconocimiento entre la comunidad letrada ${ }^{67}$. El latín y la cultura clásica conformaban un dispositivo educativo que contribuía a la formación de subjetividades al interior de la sociedad chilena, en el contexto de su organización republicana ${ }^{68}$.

Por otra parte, el estudio de los clásicos antiguos y del latín, hacia 1830, "tenía un sentido estético y también moral, pues se suponía que la cultura clásica, forjada por los pueblos más letrados y civilizados que la historia conocía, formaban el sentido del deber, el amor a la patria, la idea de libertad, de civismo y de honor" ${ }^{69}$. De allí es posible inferir que quien podía hacer gala de sus conocimientos sobre temas específicos del mundo antiguo, como los que fueron objeto de discusión en la polémica, no lo haría solo por un afán de erudición, sino de su autorepresentación como un patriota autorizado. En otras palabras, dicho bagaje daría cuenta de la educación moral y ciudadana que había recibido. Quien se probase avezado en letras clásicas

\footnotetext{
66 Serrano, Sol; Ponce de León, Macarena; y Rengifo, Francisca. Francisca. 2013. Historia de la educación en Chile (1810-2010), p. 72; Domínguez, María Carolina. 2013. Usos del latín en los procesos de configuración cultural y educativa del Cono Sur en el siglo XIX, Tesis para optar al grado de Doctora en Letras, Universidad Nacional de La Plata, Argentina, p. 31; Unceta, Luis. 2012. "Lo clásico en el siglo XVIII: cuestión de conciencia de clase”, en Cuadernos de estudios del siglo XVIII n²2, Oviedo, p. 162

${ }^{67}$ Hurtado, Edda. 2012. "Del latín al castellano o de las humanidades clásicas a las humanidades modernas en el siglo XIX chileno", en Literatura y Lingüística $\mathrm{n}^{\circ} 26$, Santiago, p. 31.

68 Poblete, Juan. 2002. Literatura chilena del siglo XIX: entre públicos lectores y figuras autoriales, Santiago, Chile, Cuarto propio, p. 212.

${ }^{69}$ Serrano, Sol; Ponce de León, Macarena; y Rengifo, Francisca. Francisca. 2013. Historia de la educación en Chile (1810-2010), p. 71.
} 
demostraba haberse formado y apropiado de las virtudes y cualidades que se presuponían como propias del humanismo y del republicanismo.

En parte, Mora lo había señalado al presentar el plan de estudios del Liceo de Chile, afirmando que la importancia de los estudios clásicos:

"no nace de un apego habitual a la antigüedad, ni de una ridícula propension á la erudicion y á la pedantería: nace del alto aprecio que merecen la historia, las instituciones, el carácter y el influjo de aquel gran pueblo, fundador de los otros que descendemos y cuyas revoluciones nos presentan los ejemplos de todas las virtudes y de todos los exesos de que es capaz el hombre"70.

Aunque difirieran en los momentos o etapas en las que debía estudiarse latín y literatura antigua, Bello y Mora concordaban en la importancia basal de estos aprendizajes ${ }^{71}$. Ello explicaría el despliegue de referencias a autores griegos y romanos, así como de algunas citas en su idioma original y la preocupación por corregir las interpretaciones etimológicas y conceptuales realizadas por sus respectivos oponentes.

La elección de los tópicos discutidos puede analizarse en el mismo sentido. En la discusión acerca de Ciro, el rey persa, Mora alababa su prudencia como una virtud característica del personaje, exaltando así una cualidad que debía ser propia de todo gobernante. Sus oponentes, en cambio, cuestionaron esta afirmación, indicando que tras las acciones del rey persa habría existido una ambición de poder, disfrazada de justicia y moderación. Así, acusaban a Mora de ingenuidad y de incapacidad de ver en algunos líderes políticos, sus intenciones particularistas ${ }^{72}$.

En el debate por la pertinencia de incluir a Isócrates y a Calidio como ejemplos de los grandes oradores, a la par con Demóstenes y Cicerón, se vislumbra el intento por definir al orador ideal y al rol que le correspondería en el contexto chileno, así como por identificarse con dicho arquetipo o cuestionar las bases de identificación del oponente.

Los debates acerca de la figura de Isócrates en el desarrollo de la retórica y en la historia de Grecia formaron parte de la tradición del género. Cicerón se había referido a él de manera constante, reconociéndolo sobre todo por su condición de maestro de grandes oradores (De Orat. II.57, II.94 y III.35). Mora siguió ese camino, pero sus críticos, desde El Popular, lo refutaron, señalando que el hecho de que el griego hubiera sido un buen maestro de retórica no implicaría que fuese un orador a la altura de Demóstenes, pues habría carecido de la fuerza

\footnotetext{
${ }^{70}$ Colección Matta Vial, Biblioteca Nacional de Chile, "Educación”, El Mercurio Chileno. Prospecto, Santiago, 1 de abril de 1828, p. 35.

${ }^{71}$ Hanisch, Walter. 1991. El latín en Chile, p. 91.

72 Biblioteca Nacional de Chile, "Liceo de Chile (III)", El Popular n¹0, 29 de mayo de 1830; "Liceo de Chile (IV)", EI Popular n¹2, 19 de junio de 1830.
} 
de pensamiento y expresión de este último ${ }^{73}$. Así, sugerían que no bastaba con enseñar elocuencia para ser plenamente un orador, lo que insinuaría, implícitamente, que José Joaquín de Mora podría haber sido objeto de similar cuestionamiento. Para serlo, había que ejercer también en el ámbito de la acción política y pública: "La verdadera cuestión es si Isócrates por sí mismo dispuso o no de la Grecia; pues el que le coloca al lado de Demóstenes como orador y hombre público, le atribuye una parte inmediata y activa en los negocios de la Grecia" ${ }^{74}$.

En el caso de Calidio, el cuestionamiento fue más fuerte. Cicerón también había hecho referencia a él (Bruto 274), como lo reconocen ambos contendores de la polémica. Pero sus lecturas sobre la relevancia del personaje son opuestas. Mientras para Mora, Calidio merecía reconocimiento por una trayectoria política que se completaba con su formación oratoria, para sus oponentes -o para Bello - el que este romano hubiese sido objeto de una referencia crítica por parte de Cicerón invalidaba su trascendencia.

Nuevamente, para la voz de El Popular, quien no cumpliera a cabalidad con el retrato del orador ideal no merecía el reconocimiento de su relevancia como personaje histórico o político. $Y$ así se atreve, finalmente, a menospreciar la trascendencia de Calidio, tanto como la del director del Liceo de Chile, confirmando que a la crítica erudita subyacía la motivación política por deslegitimar al oponente ante la comunidad letrada: "El señor Mora insiste absolutamente en que Calidio fue uno de los primeros oradores romanos, y dispuso de la república; pero repetimos que no hay tal, y que este personaje no influyó más en la república romana que el señor Mora en la de las letras" 75 .

Por el mismo motivo, la conclusión de la polémica no podría cerrarse en la discusión misma, sino en el reconocimiento público de los argumentos de uno $u$ otro contendor por parte de la comunidad cultural, la 'república de las letras', en base a las voces de autoridad de los clásicos griegos, latinos y modernos. Así lo afirmaba el anónimo participante de El Mercurio:

"Nos consta que los aficionados de nuestra capital al cultivo de la literatura, ansían por la conclusión de la controversia y por saber a quién galardonará la victoria con el triunfo; y para que puedan formar un juicio exacto sobre ella escribimos este artículo, fundando sus doctrinas, como se verá, en la autoridad de jueces irrecusables, cuyo crédito es el del mayor peso en la república de las letras"76.

Esa res publica litterarum, que se hacía eco de los principios ilustrados, canonizaba a la palabra y a la escritura, reguladas por normas gramaticales y de civilidad, como dispositivos que

\footnotetext{
73 Biblioteca Nacional de Chile, "Liceo de Chile (II)", El Popular n9, 22 de mayo de 1830.

${ }^{74}$ Biblioteca Nacional de Chile, "Liceo de Chile (IV)", El Popular n¹2, 19 de junio de 1830.

75 Biblioteca Nacional de Chile, "Liceo de Chile (IV)", El Popular n²12, 19 de junio de 1830.

${ }^{76}$ Biblioteca Nacional de Chile, “Crítica de D. Andres Bello", El Mercurio n98, Valparaíso, 30 de junio de 1830.
} 
validaban regímenes de verdad y de significación, así como la validez de las ideas ${ }^{77}$. La polémica no era, por tanto, meramente literaria. El motivo, el discurso y los asuntos de la querella solo adquirían pleno sentido como parte de una polémica de carácter público, en el esfuerzo por legitimar la autoridad cultural y el posicionamiento político de sus protagonistas y de sus partidos, en el contexto de las luchas y esfuerzos por consolidar un sistema de gobierno para Chile que, a comienzos de la década de 1830, lograra garantizar el orden y la estabilidad para la república.

\section{Conclusiones}

El análisis de los discursos de la polémica entre los líderes del Liceo de Chile y el Colegio de Santiago demuestra que su motivación no buscaba establecer, en última instancia, una acusación pedagógica o académica, sino política. En el ámbito de la organización cultural de la república, esta oposición traslucía una rivalidad por ganar la legitimidad sobre la conducción de la juventud del país y la formación de la intelectualidad que lo lideraría ${ }^{78}$. Se trataba así de una batalla por la autoridad, que evocaba el sentido latino y tradicional del concepto de auctoritas: el saber socialmente reconocido, que confiere un poder tutelar a quien lo detenta ${ }^{79}$.

El contexto que enmarcaba esta pugna pudo haber fortalecido la necesidad de consolidar esta autoridad, que era tanto cultural como política. No solo eran los tiempos del enfrentamiento entre liberales y conservadores, pipiolos y pelucones por el gobierno. Era también la época de los debates en torno al presidencialismo, al autoritarismo y al sistema que podría garantizar el orden para la república, tras la serie de ensayos constitucionales y enfrentamientos partidistas que habían caracterizado a la década de $1820^{80}$.

El análisis de los aspectos lingüísticos, etimológicos, gramaticales e historiográficos de la polémica entre Mora y Bello solo puede ponerse en valor al establecerse en un doble diálogo histórico: por una parte, con el contexto político republicano de Chile hacia 1830; por otra, con el de una larga tradición del género oratorio, canonizada en la memoria idealizada de la república romana por parte de la intelectualidad moderna.

Aunque en sí mismos pueden parecer simple objeto de erudición, la lectura conjunta y en perspectiva histórica de los argumentos permite sugerir que los detalles discutidos no constituyeron asuntos banales ni azarosos, sino que dieron sustento a la batalla política de fondo. Los errores que se señalaban mutuamente en términos gramaticales, lingüísticos o

\footnotetext{
77 Ossandón, Carlos. 2011. “Andrés Bello y la res publica litterarum”, en Universum n²6, Talca, pp. 116-117.

78 Bocaz, Luis. 2000. Andrés Bello: una biografía cultural, Bogotá, El Sello, pp. 191-192.

79 Domingo, Rafael. 1999. Auctoritas (Sobre la autoridad moral), Barcelona, Ariel, p. 7.

80 Stuven, Ana María; Cid, Gabriel. 2012. Debates republicanos en Chile. Siglo XIX, Santiago, Ediciones Universidad Diego Portales, pp. 514-516; Cruz, Nicolás. 2002. El surgimiento de la educación secundaria pública en Chile. 18431876 (El Plan de Estudios Humanista), Santiago, Centro de Investigaciones Diego Barros Arana, p. 19.
} 
historiográficos serían motivo de vergüenza para quien se preciase de orador, educador e intelectual, pues lo que estaría en cuestión, en última instancia, sería su ética del buen ciudadano y su legitimidad pública como autoridad. Esto es lo que daría a las acusaciones la connotación de un deber cívico.

El término utilizado por los contendores para referirse al círculo intelectual y social que atendió a su debate como república de las letras, sugiere el reconocimiento de una comunidad cultural que era, a su vez, una comunidad política y dirigente. La república de las letras no suponía solo una categoría social e intelectual, sino también política en su más profundo sentido: aquel que concebía a la educación como el medio indispensable para formar ciudadanía y para consolidar un sistema de organización que garantizase el ejercicio virtuoso de los miembros de la comunidad.

Aun siendo adversarios y más allá de sus diferencias partidistas, tanto José Joaquín de Mora como Andrés Bello podían comprenderse e identificarse con la república de las letras. Ambos eran miembros de una elite que compartía un imaginario y un ideario básico común para la consolidación de la naciente república chilena, cuyas claves descansaban sobre la certeza de la relación indisoluble entre educación, autoridad y política.

\section{Bibliografía}

Aedo-Richmond, Ruth. 2000. La educación privada en Chile: un estudio histórico-analítico desde el periodo colonial hasta 1990, Santiago, Ril.

Ávila M., Alamiro. 1982. Mora y Bello en Chile, Santiago, Ediciones de la Universidad de Chile.

Alberte G., Antonio. 1987. Cicerón ante la retórica, Valladolid, Universidad de Valladolid.

Amunátegui, Domingo. 1889. Los primeros años del Instituto Nacional. 1813-1835. Santiago, Imprenta

Cervantes.

Amunátegui, Miguel Luis. 1882. Vida de Don Andrés Bello, Santiago, Pedro G. Ramírez.

Amunátegui, Miguel Luis. 1888. Don José Joaquín de Mora. Apuntes biográficos, Santiago, Imprenta Nacional.

Bernard, Jacques-Emmanuel. 2008. "Rhétorique et société chez Cicéron", en Modèles linguistiques n58, Lille, pp. 47-63.

Bloomer, Martin. 2011. The school of Rome, California, University of California Press.

Bocaz, Luis. 2000. Andrés Bello: una biografía cultural, Bogotá, El Sello.

Burke, Peter. 2006. Lenguas y comunidades en la Europa moderna, Madrid, Akal.

Cicerón. 2018. Bruto: de los ilustres oradores. Traducción de Bulmaro Reyes, Ciudad de México, UNAM. Cicerón. 1879. Sobre el orador. Traducción de Marcelino Menéndez Pelayo, Imprenta Central, Madrid. Codoñer, Carmen. 1984. "Eloquentia y orator", en Estudios Clásicos, 88, Madrid, pp. 297-302.

Cruz, Nicolás. 2002. El surgimiento de la educación secundaria pública en Chile. 1843-1876 (El Plan de

Estudios Humanista), Santiago, Centro de Investigaciones Diego Barros Arana.

Domingo, Rafael. 1999. Auctoritas (Sobre la autoridad moral), Barcelona, Ariel.

Domínguez, María Carolina. 2013. Usos del latín en los procesos de configuración cultural y educativa del Cono Sur en el siglo XIX. Universidad Nacional de La Plata, Argentina, Tesis para optar al grado de Doctora en Letras. 
Dugan, John. 2009. "Rhetoric and the Roman Republic", en E. Gunderson (ed.), The Cambridge Companion to Ancient Rhetoric, Cambridge, Cambridge University Press, pp. 178-193.

Grube, Georges. 1962. "Educational, rhetorical, and literary theory in Cicero", en Phoenix vol. 16, n4, Toronto, pp. 234-257.

Hanisch, Walter. 1991. El latín en Chile. Santiago, Fondo Andrés Bello.

Hurtado, Edda. 2012. "Del latín al castellano o de las humanidades clásicas a las humanidades modernas en el siglo XIX chileno", en Literatura y Lingüística n²6, Santiago, pp. 29-46.

Iglesias, Ricardo. 2009. "El papel de la educación en la construcción del estado nacional chileno en el siglo XIX", en Cid, Gabriel y San Francisco, Alejandro, Nación y Nacionalismo en Chile. Siglo XIX, Santiago, Centro de Estudios Bicentenario, pp. 39-72.

Jaksic, Iván. 2010. Andrés Bello: la pasión por el orden, Santiago, Universitaria.

Kapust, Daniel. 2012. "Cicerón: el decorum y la moralidad de la retórica”, en Praxis filosófica n³5, Cali, pp. 257-282.

Labarca, Amanda. 1939. Historia de la enseñanza en Chile, Santiago, Imprenta Universitaria.

López E., Antonio. 2000. Esencia y objeto de la retórica, Salamanca, Ediciones Universidad de Salamanca.

Michel, Alain. 2003. Les rapports de la rhétorique et de la philosophie dans l'oeuvre de Cicéron, Leuven.

Éditions Peeters.

Monguió, Luis. 1967, Don José Joaquín de Mora y el Perú del ochocientos, Madrid, Castalia.

Orrego V., Eugenio. 1953. Don Andrés Bello, Santiago, Zigzag.

Ossandón, Carlos. 2011. "Andrés Bello y la res publica litterarum”, en Universum n²6, Talca, pp. 109122.

Pérez, Rodrigo. 2011. "Los inicios de la enseñanza del Derecho Constitucional en el Chile decimonónico: el Liceo de Chile y el Colegio de Santiago (1828-1831)", en Anuario de Estudios Americanos, vol. 68, Madrid, pp. 141-162.

Platón. 1987. Gorgias, Traducción de Julio Calonge Ruiz, Gredos, Madrid.

Platón. 1988. Fedro, Traducción de Carlos García Gual, Gredos, Madrid.

Poblete, Juan. 2002. Literatura chilena del siglo XIX: entre públicos lectores y figuras autoriales. Santiago, Cuarto propio.

Serrano, Sol, Ponce de León, Macarena, Rengifo, Francisca. 2013. Historia de la educación en Chile (18102010), Santiago, Taurus.

Silva C., Raúl. 1965. Don Andrés Bello, 1781-1865, Santiago, Andrés Bello.

Sotomayor V., Ramón. 1875. Historia de Chile durante los cuarenta años transcurridos desde 1831 hasta 1871, Santiago, Imprenta de la Estrella de Chile, Tomo I.

Stuardo, Carlos. 1950. El Liceo de Chile 1828-1831. Antecedentes para su historia, Santiago, Imprenta Universitaria.

Stuven, Ana María, Cid, Gabriel. 2012. Debates republicanos en Chile. Siglo XIX, Santiago, Ediciones Universidad Diego Portales.

Subercaseaux, Bernardo. 1997. Historia de las ideas y de la cultura en Chile, Santiago, Universitaria.

Toro, Pablo. 2018. "Ideas políticas educacionales en Chile, c.1810-c.1980", en Jaksic, Iván y Gazmuri, Susana (ed.), Historia política de Chile, 1810-2010, Santiago, Fondo de Cultura Económica, Tomo IV, pp. 103-131.

Unceta, Luis. 2012. "Lo clásico en el siglo XVIII: cuestión de conciencia de clase", en Cuadernos de estudios del siglo XVIII n²2, Oviedo, pp. 141-164.

Vidal, Santiago. 1982. Andrés Bello. Americanista y filósofo, Madrid, Oriens. 